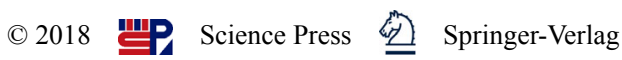

\title{
Editorial
}

\section{Understanding land system dynamics and its consequences}

\author{
WU Wenbin ${ }^{1}$, Peter H VERBURG ${ }^{2}$, TANG Huajun ${ }^{1}$
}

1. Key Laboratory of Agricultural Remote Sensing, Ministry of Agriculture/lnstitute of Agricultural Resources
and Regional Planning, Chinese Academy of Agricultural Sciences, Beijing 100081, China;
2. Institute for Environmental Studies, Vrije Universiteit Amsterdam, Amsterdam $1081 \mathrm{HV}$, The Netherlands

Land is critical to society by providing foods, fuel, fibers and many other ecosystem services that support production functions, regulate risks of natural hazards, or provide cultural and spiritual services (Verburg et al., 2013). By using the land, human have transformed a large proportion of the planet's land surface. These land use activities have enormous consequences for the environment as they alter the structure and functioning of ecosystems, and they influence how ecosystems interact with the atmosphere, aquatic systems and surrounding land (Wu et al., 2007). Land use and its dynamics have thus attracted much attention from international research community.

Under the Land Use and Land Cover Change (LUCC) project commissioned by the International Geosphere Biosphere Programme (IGBP) and the International Human Dimensions Programme on Global Environmental Change (IHDP) (Lambin and Geist, 2006), significant progress has been made in monitoring of land use and land cover changes such as deforestation and desertification, and deepening understanding of the ecological impacts of these changes. The growing group of scientists across the social, economic, geographical and natural sciences engaged in this field led to the emergence of "Land Change Science" as a separate, interdisciplinary, research field (Rindfuss et al., 2004; Turner et al., 2007). The successor of the LUCC, Global Land Project (GLP) has continued the work of LUCC (GLP, 2005). Gradually, the research interest has become more focused on the drivers and impacts of land changes, as well as their feedbacks between drivers and impacts. This has motivated an integrated socio-ecological systems perspective. In this integrated concept, land systems are acknowledged as the result of dynamic interactions within the socio-ecological system that operate across spatial and temporal scales (Verburg et al., 2013 and 2015). This perspective has also moved land change science to land system science, with a focus shifting from the most dramatic land cover changes to greater attention for subtle changes of human interactions with the natural surroundings.

This special issue of Journal of Geographical Sciences aims to communicate the latest research progress in land system science, to specifically look at some key theoretical and technical issues in investigating or modeling the dynamics of this coupled human-natural system in an urbanizing and telecoupling world, and to offer some case studies from a variety of countries or regions demonstrating the experience, algorithms, tools and models for framing these dynamics at different space and time scales. The articles in this issue were selected from the Third Open Science Meeting of the Global Land Project held from 
24th-27th October 2016 in Beijing, China. This meeting brought together large parts of the international research community working on land system issues to showcase the width and scope of ongoing research, help build a community in this highly interdisciplinary field, inspire new research, and to facilitate review, theory building and application of science in practice. All these can help to provide a comprehensive knowledge base in understanding the patterns and processes of land system changes.

Overall, the articles can be divided into three main approaches to studying land systems: land systems dynamics, land use intensity, and impacts of land change. The first four articles deal with linkages between the local and global, teleconnections and modelling approaches to understanding and influencing land system dynamics. Ju et al. (2018) use land use maps interpreted from remote sensing imagery to investigate and compare the spatio-temporal patterns of cropland conversion to urban areas, rural settlements, and industrial/transportation land from 1987 to 2010. They find that urban growth shows a greater impact on cropland loss than the expansion of rural settlements and the expansion of industrial/transportation land after 2000 (Yu et al., 2018). The contribution of rural settlement expansion decreases, yet rural settlement sees the highest percentage of traditional high-quality cropland loss. The contribution of industrial/transportation land expansion increases dramatically and is mainly distributed in major food production regions. Chen et al (2018) apply FAO statistics and GlobeLand30, and develop three indicator groups to understand the spatial-temporal changes in cultivated land in the Belt and Road Initiative region. The results show that cultivated land area in the BRI region increases $3.73 \times 10^{4} \mathrm{~km}^{2}$ between 2000 and 2010 and the increased cultivated land is mainly found in Central and Eastern Europe and Southeast Asia, while the decreased cultivated land is mostly concentrated in China. Cultivated land is mainly transferred to or from forest, grassland, artificial surfaces and bare land. There are some potentials to boost the food production in this region if their cultivated land use is intensified. Liu et al. (2018) conduct linear regression and spatial analysis to investigate the cropping structure type and cropping proportion changes at the national level for the period 1980-2011. Their findings show that China's cropping structure has undergone significant changes since 2002; the richness of cropping structure types has increased significantly and a diversified-type structure has gradually replaced the single types. Fan et al. (2018) describe the historical changes in centroids of rice, maize and wheat in China from 1949 to 2014. They find that the centroids of rice and maize experience an obvious shift in the Northeast direction, but centroids of the wheat area and production are randomly distributed along the border of the Shanxi and Henan provinces.

Two articles specifically deal with the intensity of land systems. Yan et al. (2018) extract the cropping intensity represented by the multiple cropping index (MCI) in Huang-Huai-Hai agricultural region and analyze its changes over 2000-2012. The results show that MCI in Huang-Huai-Hai region has increased from $152 \%$ to $156 \%$ in the past 12 years. More intensive use of existing croplands by increasing cropping intensity may provide an alternative for increasing the frequency of harvests each year, resulting in increased food supplies without additional cropland expansion (Dias et al., 2016; Wu et al., 2018). Shi et al. (2018) assess the intensity of cropland use and explore the influencing factors in the same Huang-Huai-Hai region. The authors find that the intensity of inputs, degree of utilization, and production increase continuously from 1996 to 2011, but the intensity of continuous 
conditions experiences an overall decline followed by a rebound towards the end of the study period.

The impacts of land system changes and their feedbacks with other systems are addressed by the next group of four articles. Xia et al. (2018) use the CLUE-S model to simulate the future land use changes over 2000-2050 in Northeast China and study their impacts on ecosystem services. They construct three different scenarios: ecological security (ESS), food security (FSS) and comprehensive development (CDS). The results can help the region to better manage land resources and guide policy interventions so as to make trade-offs between economic development and environmental protection. Tian et al. (2018) apply the AEZ model to assess the climatic change impacts on rapeseed production potential in the 2020s, 2050s, and 2080s in the Yangtze River Basin of China. They conclude that total rapeseed production would increase significantly in the middle of this century (2050s), yet the uncertainty of climate change impacts on rapeseed production also increases with time. Yao et al. (2018) model three land-use optimization scenarios (uncontrolled scenario, scale control scenario, and spatial restriction scenario) and assess their effects on SOC sequestration potential from 2010 to 2030 in Beijing. This research provides evidence to guide planning authorities in conducting land-use optimization strategies and estimating their effects on the carbon sequestration function of land-use systems. Globalized markets, decisions by distant governments, and global agenda setting influence local land use decisions to an ever-increasing degree (Liu et al., 2013). Dou et al. (2018) make a good attempt to evaluate their spillover effects of conservation efforts in Amazon by using the telecoupling framework. Surprisingly, they find that the supply-chain agreements have significantly reduced deforestation by half compared to projections within the sending system, but at the cost of increasing deforestation in the spillover system. The authors emphasize that spillover effects should be considered in the evaluation and planning of conservation efforts. Rowan (2018) develops a decision tree to locate the renewable nitrogen at a global scale by taking into account their spatial footprint and the impact on terrestrial biodiversity. They find that there are relatively few areas suitable for solar power in the western Americas, central southern Africa, eastern Asia and southern Australia, with areas most suited to wind at more extreme latitudes.

The articles in this special issue present different insights, views, and methodologies in research across the land system science community. The findings enrich our current knowledge and understanding on land system change trends, impacts of these trends on production and environment (Wu et al., 2014; Yu et al., 2018). The results provide helpful insights to assist effective land planning and land management measures to fully exploit the services of land systems while minimizing its negative impacts. The studies presented in this issue also demonstrate that land systems encompass all processes and activities related to the human use of land and are a complex issue that requires a multi-dimensional perspective. A high level of interdisciplinary and cross-scale collaboration across academic disciplines is thus needed in the future studies (Rounsevell et al., 2012).

\section{Acknowledgments}

The papers gathered in this special issue originate from the Third Open Science Meeting of the Global Land Project held from 24-27th October 2016 in Beijing, China. This research is 
supported by the National Natural Science Foundation of China (41871356) and by the China Academy of Engineering Consulting Project (2016-ZCQ-08).

\section{References}

Chen D, Yu Q, Hu Q et al., 2018. Cultivated land change in the Belt and Road Initiative region. Journal of Geographical Sciences, 28(11): 1580-1594.

Dias L C P, Pimenta F M, Santos A B et al., 2016. Patterns of land use, extensification, and intensification of Brazilian agriculture. Global Change Biology, 22(8): 2887-2903.

Dou Y, da SILVA R F B, Yang H et al., 2018. Spillover effect offsets the conservation effort in the Amazon. Journal of Geographical Sciences, 28(11): 1715-1732.

Fan L, Liang S, Chen $\mathrm{H}$ et al., 2018. Spatio-temporal analysis of the geographical centroids for three major crops in China from 1949 to 2014. Journal of Geographical Sciences, 28(11): 1672-1684.

GLP, 2005. Science Plan and Implementation Strategy IGBP Report No. 53/IHDP Report No. 19. IGBP Secretariat, Stockholm.

$\mathrm{Ju} \mathrm{H}$, Zhang Z, Zhao X et al., 2018. The changing patterns of cropland conversion to built-up land in China from 1987 to 2010. Journal of Geographical Sciences, 28(11): 1595-1610.

Lambin E F, Geist H, 2006. Land-use and Land-cover Change. Berlin Heidelberg: Springer.

Liu J, Hull V, Batistella M et al., 2013. Framing sustainability in a telecoupled world. Ecology and Society, $18(2): 26$.

Liu Z, Yang P, Wu W et al., 2018. Spatio-temporal changes of cropping structure in China during 1980-2011. Journal of Geographical Sciences, 28(11): 1659-1671.

Rindfuss R R, Walsh S J, Turner B L et al., 2004. Developing a science of land change: Challenges and methodological issues. Proceedings of the National Academy of Sciences of the United States of America, 101: 13976-13981.

Rounsevell M D A, Pedroli B, Erb K H, 2012. Challenges for land system science. Land Use Policy, 29: 899-910.

Rowan E, Seabrook L, Mcalpine C, 2018. Global prioritisation of renewable nitrogen for biodiversity conservation and food security. Journal of Geographical Sciences, 28(11): 1567-1579.

Shi S, Han Y, Yu W et al., 2018. Spatio-temporal differences and factors influencing intensive cropland use in the Huang-Huai-Hai Plain. Journal of Geographical Sciences, 28(11): 1626-1640.

Tian Z, Ji Y, Sun L et al., 2018. Changes in production potentials of rapeseed in the Yangtze River Basin of China under climate change: A multi-model ensemble approach. Journal of Geographical Sciences, 28(11): 1700-1714.

Turner BL, Lambin EF, Reenberg A et al., 2007. The emergence of land change science for global environmental change and sustainability. Proceedings of the National Academy of Sciences of the United States of America, 104: 20666-20671.

Verburg P H, Crossman N, Ellis E C et al., 2015. Land system science and sustainable development of the earth system: A global land project perspective. Anthropocene, 12: 29-41.

Verburg P H, Erb K, Mertz O et al., 2013. Land system science: Between global challenges and local realities. Current Opinion in Environmental Sustainability, 5(5): 433-437.

Wu W, Shibasaki R, Yang P et al., 2007. Global-scale modelling of future changes in sown areas of major crops. Ecological Modelling, 208: 378-390.

Wu W, Verburg P H, Tang H, 2014. Climate change and the food production system: Impacts and adaptation in China. Regional Environmental Change, 14: 1-5.

Wu W, Yu Q, You L et al., 2018. Global cropping intensity gaps: Increasing food production without cropland expansion. Land Use Policy, 76: 515-525.

Xia T, Wu W, Zhou Q et al., 2018. Modeling the spatio-temporal changes in land uses and its impacts on ecosystem services in Northeast China over 2000-2050. Journal of Geographical Sciences, 28(11): 1611-1625.

Yao J, Kong X, 2018. Modeling the effects of land-use optimization on the soil organic carbon sequestration potential. Journal of Geographical Sciences, 28(11): 1641-1658.

Yan H, Liu F, Niu Z et al., 2018. Changes of multiple cropping in Huang-Huai-Hai agricultural region, China. Journal of Geographical Sciences, 28(11): 1685-1699.

Yu Q, Hu Q, van Vliet J et al., 2018. GlobeLand30 shows little cropland area loss but greater fragmentation in China. International Journal of Applied Earth Observation and Geoinformation, 66: 37-45.

Yu Q, van Vliet J, Verburg P H et al., 2018. Harvested area gaps in China between 1981 and 2010: Effects of climatic and land management factors. Environmental Research Letters, 13: 044006. 